\title{
Intracoronary Eptifibatide During Primary Percutaneous Coronary Intervention in Early Versus Late Presenters with ST Segment Elevation Myocardial Infarction: A Randomized Trial
}

\author{
Ayman Elbadawi - Gerald Gasioch · Islam Y. Elgendy (D) Ahmed N. Mahmoud • \\ Le Dung Ha • Haitham Al Ashry • Hend Shahin • Mohamed A. Hamza • \\ Ahmed S. Abuzaid · Marwan Saad \\ Received: October 17, 2016 / Published online: November 14, 2016 \\ (C) The Author(s) 2016. This article is published with open access at Springerlink.com
}

\section{ABSTRACT}

Introduction: The role of intracoronary (IC) eptifibatide in primary percutaneous coronary intervention (PPCI) for ST segment elevation myocardial infarction (STEMI) and whether time of patient presentation affects this role are unclear. We sought to evaluate the benefit of IC eptifibatide use during primary PCI in

Enhanced content To view enhanced content for this article go to http://www.medengine.com/Redeem/ 4717F06012E1F795.

A. Elbadawi · L. D. Ha

Department of Internal Medicine, Rochester General Hospital, Rochester, NY, USA

\section{A. Elbadawi · M. A. Hamza · M. Saad}

Department of Cardiovascular Medicine, Ain Shams Medical School, Cairo, Egypt

\section{G. Gasioch}

Department of Cardiovascular Medicine, Rochester General Hospital, Rochester, NY, USA

I. Y. Elgendy $(\varangle) \cdot$ A. N. Mahmoud

Division of Cardiovascular Medicine, University of Florida, Gainesville, FL, USA

e-mail: Islam.elgendy@medicine.ufl.edu

\section{H. A. Ashry}

Division of Pulmonary, Critical Care and Sleep

Medicine, Department of Medicine, Medical

University of South Carolina, Charleston, SC, USA early STEMI presenters compared to late STEMI presenters.

Methods: We included 70 patients who presented with STEMI and were eligible for PPCI. On the basis of symptom-to-door time, patients were classified into two arms: early ( $<3 \mathrm{~h}, n=34)$ vs late ( $\geq 3 \mathrm{~h}, n=36)$ presenters. They were then randomized to local IC eptifibatide infusion vs standard care (control group). The primary end point was post-PCI myocardial blush grade (MBG) in the culprit vessel. Other end points included corrected

\section{H. Shahin}

Department of Pharmaceutics and Pharmaceutical Technology, Faculty of Pharmaceutical Sciences and Pharmaceutical Industries, Future University in Egypt, Cairo, Egypt

\section{A. S. Abuzaid}

Sidney Kimmel Medical College at Thomas Jefferson University/Christiana Care Health System, Newark, DE, USA

\section{Saad}

Division of Cardiovascular Medicine, Department of Medicine, University of Arkansas for Medical Sciences, Little Rock, AR, USA 
TIMI frame count (cTFC), ST segment resolution (STR) $\geq 70 \%$, and peak CKMB.

Results: In the early presenters arm, no difference was observed in MBG results $\geq 2$ in the IC eptifibatide and control groups (100\% vs $82 \% ; p=0.23)$. In the late presenters arm, the eptifibatide subgroup was associated with improved $M B G \geq 2$ (100\% vs 50\%; $p=0.001)$. IC eptifibatide in both early and late presenters was associated with less cTFC (early presenters 19 vs. $25.6, p=0.001$; late presenters 20 vs. $31.5, p<0.001$ ) and less peak CKMB (early presenters 210 vs $260 \mathrm{IU} / \mathrm{L}, p=0.006$; late presenters 228 vs $318 \mathrm{IU} / \mathrm{L}, \quad p=0.005)$ compared with the control group. No difference existed between both groups in STR index in early and late presenters.

Conclusion: IC eptifibatide might improve the reperfusion markers during PPCI for STEMI patients presenting after $3 \mathrm{~h}$ from onset of symptoms. A large randomized study is recommended to ascertain the benefits of IC eptifibatide in late presenters on clinical outcomes.
Keywords: Intracoronary

Percutaneous coronary intervention; ST segment elevation myocardial infarction

\section{INTRODUCTION}

Despite the established role of primary percutaneous coronary intervention (PCI) in improving the outcomes in patients presenting with ST segment elevation myocardial infarction (STEMI), a significant portion of patients do not achieve optimal angiographic or clinical reperfusion outcomes [1]. This is in part related to what is known as the "no-reflow" phenomenon, which was described as microvascular obstruction (MVO) despite angiographic vessel patency. The incidence of no-reflow varied from $12 \%$ to $29 \%$ in prior studies [2,3] and is associated with increased infarct size, reduced left ventricular (LV) function, and increased mortality in STEMI patients [1].

Glycoprotein (GP) IIb/IIIa inhibitors have been a field of interest for many studies as an intervention to reduce MVO and no-reflow during primary PCI. Results regarding its efficacy as well as the preferred route of administration, intracoronary (IC) versus intravenous (IV), have been controversial $[4,5]$. Overall, the existing body of evidence is in favor of using GP IIb/IIIa inhibitors as a bailout therapy in selective conditions with heavy thrombus burden or procedural-related thrombotic complications, rather than using them routinely in all patients $[6,7]$.

The duration of ischemia defined as the time elapsed from symptom onset until therapy was proven to correlate inversely with myocardial salvage as well as survival rates in patients with STEMI [8-10]. Late presenters are associated with higher magnitude of infarct size and microvascular obstruction compared to STEMI patients who undergo early recanalization of occluded arteries [11]. Moreover, thrombus composition tends to differ according to the time of presentation. Fresh occlusive thrombi are rich in platelets and loose fibrin strands, whereas older thrombi tend to be rich in red blood cells and fibrin [12]. The efficacy of fibrinolytic therapy has been shown to be strongly impacted by presentation time, with best outcomes in patients receiving the drug within $2 \mathrm{~h}$ from symptom onset [13].

In this hypothesis-generating study, we sought to evaluate the benefit of routine IC eptifibatide use during primary PCI in early STEMI presenters compared to late STEMI presenters. 


\section{METHODS}

\section{Study Design and Population}

This is a single-center randomized controlled open-labeled trial. We enrolled 78 patients who presented to our tertiary medical center in the period from February 2015 to December 2015 with acute STEMI. STEMI was defined as new ST segment elevation at the J point in at least two contiguous leads of at least $2 \mathrm{~mm}(0.2 \mathrm{mV})$ in men or at least $1.5 \mathrm{~mm}(0.15 \mathrm{mV})$ in women in leads V2-V3 and/or of at least $1 \mathrm{~mm}(0.1 \mathrm{mV})$ in other leads on a 12-lead electrocardiogram (ECG) [14]. Patients were included in the study if the onset of symptoms was within no more than $12 \mathrm{~h}$ and they were eligible for primary PCI. Patients were excluded if they (1) had history of ischemic stroke within the previous 30 days or intracranial hemorrhage at any time; (2) presented with cardiogenic shock (i.e., Killip class IV); (3) had platelet count less than 100,000 cells $/ \mu \mathrm{L}$; (4) initially received fibrinolytic therapy; or (5) had history of PCI or coronary artery bypass grafting (CABG).

\section{Generation of Treatment Assignment}

After confirming the eligibility to be included in our study, patients were classified on the basis of their symptom-to-door time (defined as time from onset of chest pain until first medical contact) into two arms: early presenters (i.e., $<3 \mathrm{~h}$ ) versus late presenters (i.e., $\geq 3 \mathrm{~h}$ ). Patients in each arm were then randomized (1:1 using computer-based random sequence generation) into two subgroups. The first subgroup in each arm received local IC eptifibatide infusion (intervention group), while the second group underwent conventional primary PCI (control group). Protocol of IC eptifibatide infusion involved local drug delivery via perfusion catheter with 2 bolus doses of $180 \mu \mathrm{g} / \mathrm{kg}$ each, given $10 \mathrm{~min}$ apart, and followed by an IV maintenance dose of $2.0 \mu \mathrm{g} \mathrm{kg}^{-1} \mathrm{~min}^{-1}$ for $12 \mathrm{~h}$.

All patients received $325 \mathrm{mg}$ of chewable aspirin and $600 \mathrm{mg}$ of clopidogrel before the index procedure and $70 \mathrm{IU} / \mathrm{kg}$ unfractionated heparin during the procedure. The vascular access and the use of adjunctive therapy such as thrombectomy catheters were left to the operator's discretion. Aspirin, angiotensin-converting enzyme inhibitors, beta-blockers and statins were prescribed after PCI in the absence of contraindications. Clopidogrel (75 mg) was continued daily for at least 12 months after PCI.

All patients had laboratory investigations done including daily complete blood count (CBC), serum creatinine level, serum troponin on admission and after $4-6 \mathrm{~h}$, and creatine kinase myocardial band (CKMB) levels every $6 \mathrm{~h}$ till normalization.

All procedures followed were in accordance with the ethical standards of the responsible committee on human experimentation (institutional and national) and with the Declaration of Helsinki of 1964, as revised in 2013. Informed consent was obtained from all patients for being included in the study.

As this study was intended as a pilot study to test this hypothesis, the study was not registered. The authors intend to register the larger study once it is pursued.

\section{Outcomes and Definitions}

The main outcome of this study included post-primary PCI myocardial blush grading (MBG). MBG was evaluated in left lateral view after the PCI; and outcome measure of achievement of $M B G \geq 2$ was defined as moderate opacification or more of the 
myocardium, and cleared normally at the end of the washout phase [15]. An independent cardiologist, expert in cardiac catheterization, who was unaware of the randomization reviewed the coronary angiography to assess the MBG and the corrected thrombolysis in myocardial infarction frame count (CTFC).

\section{Other Outcomes of Interest Included}

(a) CTFC was defined as the number of cine-frames required for contrast to reach the following defined distal landmarks of the three main epicardial arteries: left anterior descending (LAD) - the distal bifurcation point of the LAD artery; right coronary artery (RCA)—the first branch of the posterolateral artery of the RCA; and left circumflex artery (LCX)-the most distal bifurcation of the obtuse marginal branch of the LCX system. A correction factor was applied to compensate for the longer length of the LAD compared with the LCX and RCA (the number of frames required for contrast to traverse the LAD was divided by 1.7) [16].

(b) Achievement of full ST segment resolution (STR) after primary PCI was defined as $\geq 70 \%$ resolution of the ST segment elevation [17]. ST segment elevation was evaluated in 12-lead EKG done within 10 min of the first medical contact and at 60 min after reperfusion in the lead of maximum ST segment elevation. PR segment was the reference baseline. Evaluation was conducted by a single investigator blinded to randomization.

(c) Infarct size after primary PCI was assessed by the peak levels of CKMB enzymes.

\section{Statistical analysis}

Statistical analyses were performed using SPSS $^{\circledR}$ Statistics 20. Qualitative variables were compared using Chi-square test $\left(\mathrm{X}^{2}\right)$ among different study groups. If the expected count was less than 5 in more than $20 \%$ of the cells, either Fisher's exact (FET) or Monte Carlo corrections were used instead. To compare quantitative variables between two groups, independent $t$ test was used if their distributions were normal; and Mann-Whitney test was used if they were not. To compare quantitative and qualitative outcomes between IC eptifibatide and control groups while controlling for confounders, multiple linear and logistic regression analyses were used.

The effect size was measured using relative risk (RR) and 95\% confidence intervals (CI) with qualitative outcomes, and mean difference and 95\% CI with quantitative normally distributed outcomes. In case of quantitative outcomes not following the normal distribution, the effect size, $r$, was calculated by dividing the $z$ score by the square root of the sample size. The effect size was defined as small if $|r|<0.3$, medium if $|r|$ ranged from 0.3 to 0.5 , and strong if $|r|>0.5$. Interaction tests were explored using Breslow-Day test [18] with qualitative outcomes and multiple linear regressions with continuous outcomes. Significant test results were quoted as two-tailed probabilities, and judged at the 5\% level.

\section{RESULTS}

Of 78 patients screened for enrollment, 70 patients were eligible for inclusion in the study (one patient had a prior PCI, three patients had prior CABG, two patients had a platelet count $<100,000$ cells $/ \mu \mathrm{L}$, while two patients had inadequate angiographic images to assess MBG). The patients were classified according to their symptom-to-door time into early presenters $(<3 \mathrm{~h}, n=34)$ versus late presenters ( $\geq 3 \mathrm{~h}, n=36$ ). Patients in each arm 
were further randomized into intervention (receiving IC eptifibatide during the primary PCI) and control groups. The distribution of all baseline characteristics, except that of the gender, was similar between the IC eptifibatide and control groups (Table 1). Among early presenters, there were significantly more female patients in the IC eptifibatide group compared to the control group $(p=0.018)$.

In the early presenters group, no difference was observed in the main outcome of $\mathrm{MBG} \geq 2$ in the intervention group compared with control group ( $100 \%$ vs $82 \%$; RR $=1.2$; $95 \% \mathrm{CI}$ $0.97-1.51 ; p=0.23$ ) (Fig. 1). The eptifibatide subgroup, however, was associated with improved median cTFC (19 vs 25; $r=0.6$; $p<0.001$ ) (Fig. 2) and lower peak CKMB values (210 vs $260 \mathrm{IU} / \mathrm{L} ; r=0.5 ; p=0.006$ ) (Fig. 3), compared with the control subgroup. STR $\geq 70 \%$ was not significantly different between both subgroups (65\% vs 35\%; RR $=1.8 ; 95 \% \mathrm{CI}$ $0.9-3.8 ; p=0.09)$. No difference in these results was observed after adjustment for female gender, which was over-represented in the IC eptifibatide subgroup.

In the late presenters arm, the eptifibatide subgroup was associated with improved main outcome of $M B G \geq 2$ (100 vs $50 \%$; $R R=2 ; 95 \%$ CI $1.3-3.2 ; p=0.001)$ compared with the control subgroup (Fig. 1). Similar to early presenters, the eptifibatide subgroup was

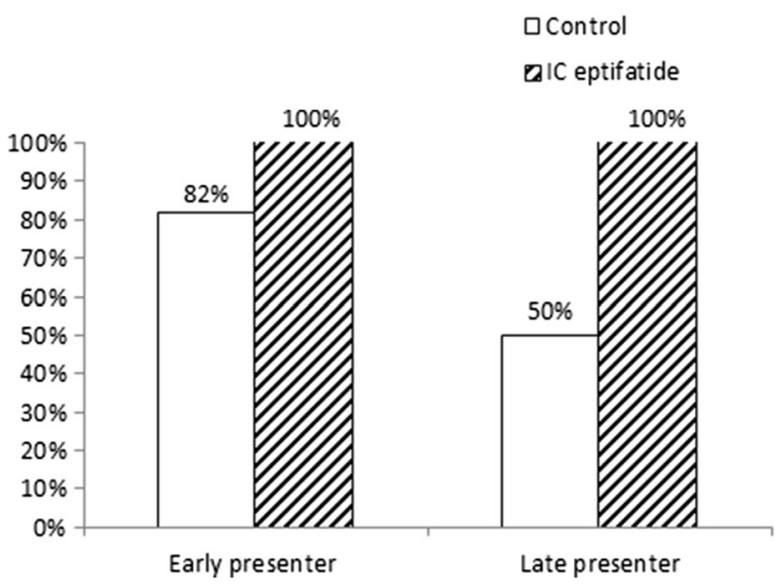

Fig. 1 Achievement of $M B G \geq 2$ in early and late presenters. $I C$ intracoronary, $M B G$ myocardial blush grade

Table 1 Comparison of baseline characteristics between Early and Late presenters

\begin{tabular}{|c|c|c|c|c|c|c|}
\hline \multirow{2}{*}{$\begin{array}{l}\text { Baseline } \\
\text { characteristics }\end{array}$} & \multicolumn{3}{|c|}{ Early presenters $(n=34)$} & \multicolumn{3}{|c|}{ Late presenters $(n=36)$} \\
\hline & $\begin{array}{l}\text { IC eptifibatide } \\
(n=17)\end{array}$ & $\begin{array}{l}\text { Control } \\
(n=17)\end{array}$ & $p$ value ${ }^{*}$ & $\begin{array}{l}\text { IC eptifibatide } \\
(n=18)\end{array}$ & $\begin{array}{l}\text { Control } \\
(n=18)\end{array}$ & $p$ value $^{*}$ \\
\hline $\begin{array}{l}\text { Age, years, mean } \\
\text { (SD) }\end{array}$ & $53.1(8.9)$ & $52.5(7.4)$ & 0.835 & $49.9(10.3)$ & $55.7(11.2)$ & 0.116 \\
\hline Female, $n(\%)$ & $6(35)$ & $0(0)$ & 0.018 & $1(6)$ & $2(11.1)$ & 1.000 \\
\hline Smoking, $n(\%)$ & $10(59)$ & $14(82)$ & 0.132 & $15(83)$ & $16(89)$ & 1.000 \\
\hline HLD, $n(\%)$ & $9(53)$ & $10(59)$ & 0.730 & $8(44)$ & $8(44)$ & 1.000 \\
\hline $\mathrm{DM}, n(\%)$ & $6(35)$ & $6(35)$ & 1.000 & $7(39)$ & $6(33)$ & 0.729 \\
\hline HTN, $n(\%)$ & $7(41)$ & $4(24)$ & 0.271 & $5(28)$ & $7(39)$ & 0.480 \\
\hline $\mathrm{FH}, n(\%)$ & $5(29)$ & $1(6)$ & 0.175 & $3(17)$ & $2(11)$ & 1.000 \\
\hline
\end{tabular}

$I C$ intracoronary, SD standard deviation, $H T N$ hypertension, $D M$ diabetes mellitus, FH family history of premature coronary artery disease

* $p$ value for statistical test comparing IC eptifibatide and control groups 


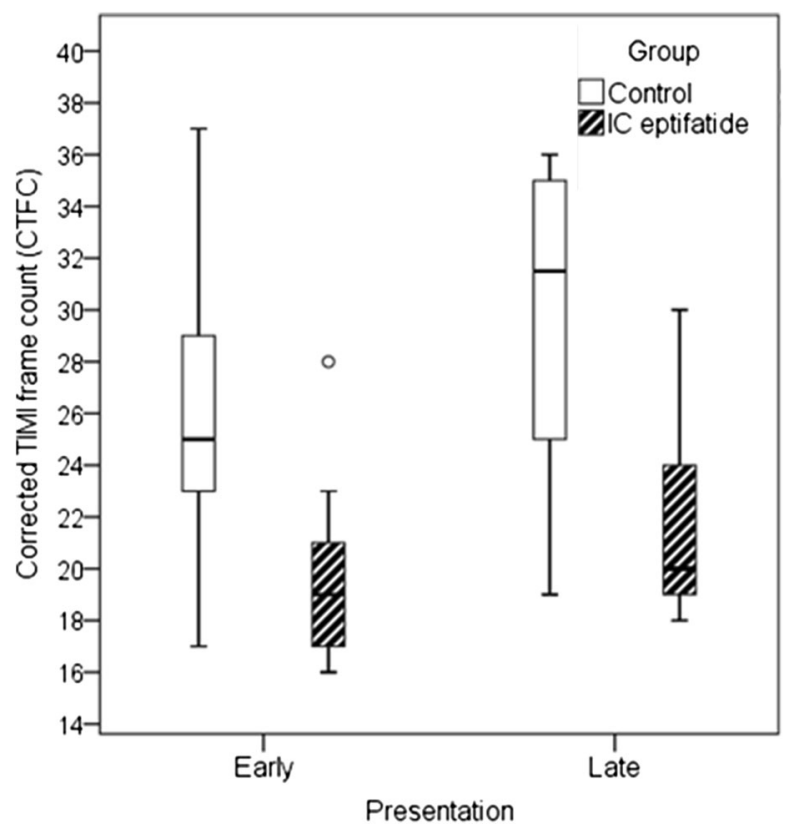

Fig. 2 Box plot indicating the distribution of cTFC between control and IC eptifibatide groups and between early and late presenters. $c T F C$ corrected TIMI frame count, $I C$ intracoronary

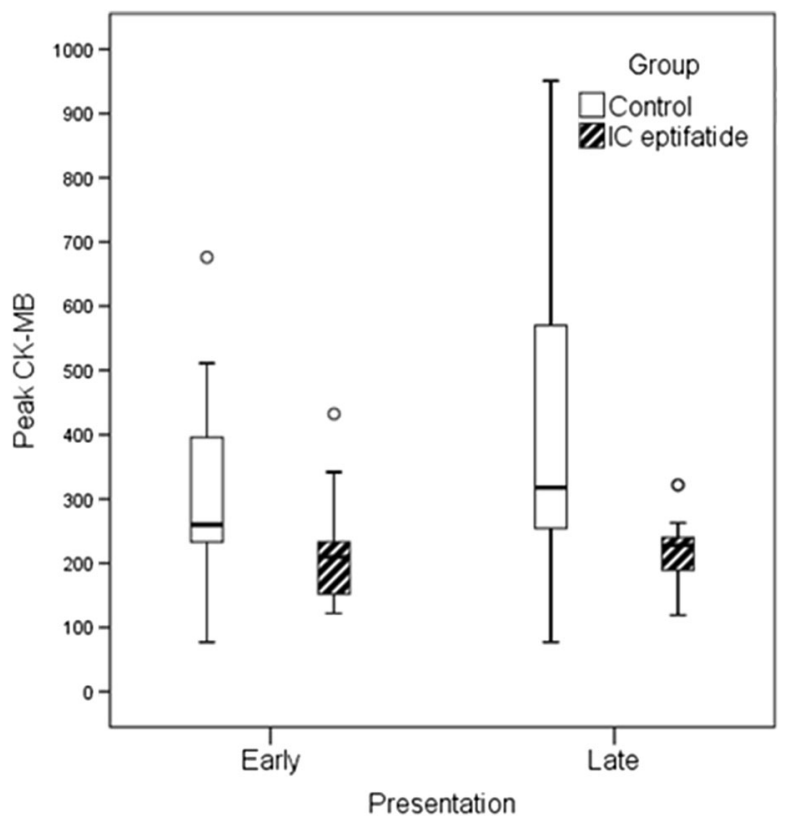

Fig. 3 Box plot indicating the distribution of peak CKMB between control and IC eptifibatide groups and between early and late presenters. $C K M B$ creatine kinase myocardial band, $I C$ intracoronary associated with improved median cTFC (20 vs $31.5 ; r=-0.6 ; p<0.001$ ) (Fig. 2) and lower peak CKMB (228 vs $318 \mathrm{IU} / \mathrm{L} ; r=-0.5 ; p=0.005)$ (Fig. 3) compared with the control group. STR $\geq 70 \%$ remained similar in both subgroups $(28 \%$ vs $22 \% ; \mathrm{RR}=1.3 ; 95 \%$ CI $0.4-3.9 ; p>0.99$ ). Table 2 illustrates the comparison of outcomes between IC eptifibatide and control groups.

\section{DISCUSSION}

In this prospective randomized study including 70 patients with acute STEMI, we sought to assess the efficacy of IC eptifibatide in reducing the no-reflow phenomenon during primary PCI compared with standard care, in early $(<3 \mathrm{~h})$ and late $(\geq 3 \mathrm{~h})$ STEMI presenters. Our study demonstrated improvement in the main outcome of MBG $\geq 2$ in the late STEMI presenters receiving IC eptifibatide compared to standard primary PCI; however, no benefit was observed in early STEMI presenters. Both early and late STEMI presenters receiving IC eptifibatide showed improvement in CTFC and infarct size determined by peak CKMB levels but without significant difference in STR $\geq 70 \%$.

The role of routine use of GP IIb/IIIa inhibitors to improve myocardial reperfusion and prevent the no-reflow phenomenon during primary PCI is unclear [19-21], and the bailout use of these agents during circumstances at high risk of thrombus-related complications remains the standard protocol [14]. Furthermore, the appropriate route of administration of GP IIb/ IIIa (intracoronary versus intravenous) is still debatable [5, 22-24]. IC eptifibatide was found to achieve better outcomes compared to conventional PCI and aspiration thrombectomy devices during primary PCI in STEMI patients [4]. 





The objective of our study was driven by the fact that the presentation time for STEMI patients significantly impacts the outcomes of primary PCI. Studies have shown an increase in short- and long-term mortality with progressive delays between symptom onset and PCI [25], where each 30-min delay from symptom onset was associated with around $8 \%$ increase in the relative risk of mortality at 1 year [26].

To our knowledge, this is the first study to evaluate whether IC eptifibatide in addition to primary PCI would reduce the risk of no-reflow compared with conventional care based on pain-to-door time of STEMI patients. Hence, a $2 \times 2$ study protocol was performed, where we divided the included patients into early and late STEMI presenters, and then randomized each arm to receive either primary PCI with IC eptifibatide versus conventional primary PCI. We chose to provide eptifibatide through IC perfusion catheter, rather than IV route, to achieve higher concentration of the drug at the site of the thrombus, aiming for superior dissociation of the bound fibrinogen and improvement of microvascular perfusion [27, 28].

The superior achievement of the main outcome of $M B G \geq 2$ seen with eptifibatide in late STEMI presenters compared to the control group, and the failure to observe such benefit in the early presenters arm, could be explained by the propensity of the former arm towards higher microvascular obstruction [11]. It might also be attributed to the difference in thrombus composition in late versus early presenters [12]. Ischemic time was proven to highly impact thrombi composition, through a positive correlation with fibrin content and negative correlation with platelet content and soluble CD40 ligand [29]. Furthermore, recent studies have demonstrated that higher concentrations of GP IIb/IIIa receptor antagonists are necessary to effectively disaggregate stable and aged aggregates compared with newly formed thrombi [30]. The absence of an observed clinical benefit through lack of improvement in STR $\geq 70 \%$ is likely related to the small sample size of our study.

The use of IC eptifibatide was associated with improvement in cTFC as well as reduction in peak CKMB values compared with conventional care in both early and late presenters. However, the discrepancy between such benefit and lack of improvement of MBG in the early presenters could be explained by the fact that MBG is a more sensitive indicator of microvascular perfusion compared with TIMI flow which mainly represents macrovascular patency $[15,16,31,32]$.

\section{Limitations}

We acknowledge the following as limitations for our study. This study was conducted in a single center with a small sample size, which could have precluded a more robust analysis. Also, the study was not double-blinded. However, seeking to eliminate potential source of bias, investigators evaluating end points were blinded to the treatment groups. In addition, the use of more advanced modalities such as cardiac magnetic resonance would have provided superior assessment of outcomes (e.g., infarct size).

\section{CONCLUSION}

Intracoronary eptifibatide may improve the reperfusion outcomes during primary PCI for STEMI patients presenting after $3 \mathrm{~h}$ from onset of symptoms. Future perspective should be directed towards larger-sized studies with 
emphasis on clinical end points in order to better evaluate the results of our study.

\section{ACKNOWLEDGEMENTS}

No funding or sponsorship was received for this study or publication of this article. All named authors meet the International Committee of Medical Journal Editors (ICMJE) criteria for authorship for this manuscript, take responsibility for the integrity of the work as a whole, and have given final approval for the version to be published.

Disclosures. Ayman Elbadawi, Gerald Gasioch, Islam Y. Elgendy, Ahmed N. Mahmoud, Le Dung Ha, Haitham Al Ashry, Hend Shahin, Mohamed A. Hamza, A. S. Abuzaid, and Marwan Saad have nothing to disclose.

Compliance with Ethics Guidelines. All procedures followed were in accordance with the ethical standards of the responsible committee on human experimentation (institutional and national) and with the Declaration of Helsinki of 1964, as revised in 2013. Informed consent was obtained from all patients for being included in the study.

Data Availability. The datasets and/or analyzed data for the current study are available from the corresponding author upon request.

Open Access. This article is distributed under the terms of the Creative Commons Attribution-NonCommercial 4.0 International License (http://creativecommons.org/licenses/ by-nc/4.0/), which permits any noncommercial use, distribution, and reproduction in any medium, provided you give appropriate credit to the original author(s) and the source, provide a link to the Creative Commons license, and indicate if changes were made.

\section{REFERENCES}

1. Stone GW, Peterson MA, Lansky AJ, Dangas G, Mehran R, Leon MB. Impact of normalized myocardial perfusion after successful angioplasty in acute myocardial infarction. J Am Coll Cardiol. 2002;39(4):591-7.

2. Dibra A, Mehilli J, Dirschinger J, et al. Thrombolysis in myocardial infarction myocardial perfusion grade in angiography correlates with myocardial salvage in patients with acute myocardial infarction treated with stenting or thrombolysis. J Am Coll Cardiol. 2003;41(6):925-9.

3. Piana RN, Paik GY, Moscucci M, et al. Incidence and treatment of 'no-reflow' after percutaneous coronary intervention. Circulation. $1994 ; 89(6): 2514-8$.

4. Hamza MA, Galal A, Suweilam S, Ismail M. Local intracoronary eptifibatide versus mechanical aspiration in patients with acute ST-elevation myocardial infarction. International journal of vascular medicine. 2014. doi:10.1155/2014/294065

5. Thiele H, Wöhrle J, Hambrecht $\mathrm{R}$, et al. Intracoronary versus intravenous bolus abciximab during primary percutaneous coronary intervention in patients with acute ST-elevation myocardial infarction: a randomised trial. Lancet. 2012;379(9819):923-31.

6. Steg PG, James SK, Atar D, et al. ESC guidelines for the management of acute myocardial infarction in patients presenting with ST-segment elevation. Eur Heart J. 2012;33(20):2569-619.

7. O'Gara PT, Kushner F, Ascheim D. ACCF/AHA guideline. Circulation. 2013;127:529-55.

8. Francone M, Bucciarelli-Ducci C, Carbone I, et al. Impact of primary coronary angioplasty delay on myocardial salvage, infarct size, and microvascular damage in patients with ST-segment elevation myocardial infarction: insight from cardiovascular magnetic resonance. J Am Coll Cardiol. 2009;54(23):2145-53.

9. De Luca G, Suryapranata H, Ottervanger JP, Antman EM. Time delay to treatment and mortality in primary angioplasty for acute myocardial infarction every minute of delay counts. Circulation. 2004;109(10):1223-5. 
10. Raitt MH, Maynard C, Wagner GS, Cerqueira MD, Selvester RH, Weaver WD. Relation between symptom duration before thrombolytic therapy and final myocardial infarct size. Circulation. 1996;93(1):48-53.

11. Brodie BR, Webb J, Cox DA, et al. Impact of time to treatment on myocardial reperfusion and infarct size with primary percutaneous coronary intervention for acute myocardial infarction (from the EMERALD Trial). Am J Cardiol. 2007;99(12):1680-6.

12. Beygui F, Collet J-P, Nagaswami C, Weisel JW, Montalescot G. Architecture of intracoronary thrombi in ST-elevation acute myocardial infarction time makes the difference. Circulation. 2006;113(2):e21-3.

13. White HD, Chew DP. Acute myocardial infarction. Lancet. 2008;372(9638):570-84.

14. O'Gara PT, Kushner FG, Ascheim DD, et al. 2013 ACCF/AHA guideline for the management of ST-elevation myocardial infarction: a report of the American College of Cardiology Foundation/ American Heart Association Task Force on Practice Guidelines. J Am Coll Cardiol. 2013;61(4):e78-140.

15. Henriques JP, Zijlstra F, van't Hof AW, et al. Angiographic assessment of reperfusion in acute myocardial infarction by myocardial blush grade. Circulation. 2003;107(16):2115-9.

16. Gibson CM, Cannon CP, Daley WL, et al. TIMI frame count a quantitative method of assessing coronary artery flow. Circulation. 1996;93(5):879-88.

17. Schröder R. Prognostic impact of early ST-segment resolution in acute ST-elevation myocardial infarction. Circulation. 2004;110(21):e506-10.

18. Breslow NE, Day NE, Davis W. Statistical methods in cancer research. Lyon: International Agency for Research on Cancer; 1987.

19. Stone GW, Witzenbichler B, Guagliumi G, et al. Bivalirudin during primary PCI in acute myocardial infarction. N Engl J Med. 2008;358(21):2218-30.

20. De Luca G, Suryapranata H, Stone GW, et al. Abciximab as adjunctive therapy to reperfusion in acute ST-segment elevation myocardial infarction: a meta-analysis of randomized trials. JAMA. 2005;293(14):1759-65.

21. Han Y, Guo J, Zheng Y, et al. Bivalirudin vs heparin with or without tirofiban during primary percutaneous coronary intervention in acute myocardial infarction: the BRIGHT randomized clinical trial. JAMA. 2015;313(13):1336-46.
22. Esfandi A, Fotouhi M, Allami A, Ebrahimi M. Comparison between the outcomes of intracoronary and intravenous administration of eptifibatide during primary percutaneous coronary intervention in patients with acute ST-elevation myocardial infarction. J Atheroscler Thromb. 2016;23(4):465-76.

23. Deibele AJ, Jennings LK, Tcheng JE, Neva C, Earhart $\mathrm{AD}$, Gibson CM. Intracoronary eptifibatide bolus administration during percutaneous coronary revascularization for acute coronary syndromes with evaluation of platelet glycoprotein IIb/IIIa receptor occupancy and platelet function the intracoronary eptifibatide (ICE) trial. Circulation. 2010;121(6):784-91.

24. Sanati HR, Zahedmehr A, Firouzi A, et al. Intracoronary versus Intravenous eptifibatide during percutaneous coronary intervention for acute ST-segment elevation myocardial infarction; a randomized controlled trial. Cardiovasc Interv Ther. 2016:1-7. doi:10.1007/s12928-016-0418-9.

25. Rathore SS, Curtis JP, Chen J, et al. Association of door-to-balloon time and mortality in patients admitted to hospital with ST elevation myocardial infarction: national cohort study. BMJ. 2009;338:b1807.

26. Levine GN, Bates ER, Blankenship JC, et al. 2015 ACC/AHA/SCAI focused update on primary percutaneous coronary intervention for patients with ST-elevation myocardial infarction: an update of the 2011 ACCF/AHA/SCAI guideline for percutaneous coronary intervention and the 2013 ACCF/AHA guideline for the management of ST-elevation myocardial infarction: a report of the American College of Cardiology/American Heart Association Task Force on Clinical Practice Guidelines and the Society for Cardiovascular Angiography and Interventions. Catheter Cardiovasc Interv. 2016;87(6):1001-19.

27. Moser M, Bertram U, Peter K, Bode C, Ruef J. Abciximab, eptifibatide, and tirofiban exhibit dose-dependent potencies to dissolve platelet aggregates. J Cardiovasc Pharmacol. 2003;41(4):586-92.

28. Goto S, Tamura N, Ishida H. Ability of anti-glycoprotein IIb/IIIa agents to dissolve platelet thrombi formed on a collagen surface under blood flow conditions. J Am Coll Cardiol. 2004;44(2):316-23.

29. Silvain J, Collet J-P, Nagaswami C, et al. Composition of coronary thrombus in acute myocardial infarction. J Am Coll Cardiol. 2011;57(12):1359-67. 
30. Speich H, Earhart A, Hill S, et al. Variability of platelet aggregate dispersal with glycoprotein IIb-IIIa antagonists eptifibatide and abciximab. J Thromb Haemost. 2009;7(6):983-91.

31. Hoffmann R, Haager P, Lepper W, Franke A, Hanrath P. Relation of coronary flow pattern to myocardial blush grade in patients with first acute myocardial infarction. Heart. 2003;89(10):1147-51.
32. Abdelaziz HK, Elkilany W, Khalid S, Sabet S, Saad M. Efficacy and safety of intracoronary verapamil versus sodium nitroprusside for the prevention of microvascular obstruction during primary percutaneous coronary intervention for ST-segment elevation myocardial infarction. Coronary Artery Dis. 2016. doi:10.1097/MCA. 0000000000000423. 